\title{
DOIGT EN LORGNETTE AND CONCENTRIC BONE ATROPHY ASSOCIATED WITH HEALED YAWS OSTEITIS
}

\author{
Report of Two Cases \\ B. S. Jones, Cape Town, South Africa \\ From the Princess Alice Orthopaedic Hospital, Cape Town
}

Marie and Léri (1913) applied the term doigt en lorgnette to a condition in which the digits were shortened but their skin redundant, so that they could be pulled out to their full length. The common cause of doigt en lorgnette is a chronic absorptive arthritis, usually termed arthritis mutilans, which Solomon and Stecher (1950) considered to be an unusual variant or extreme manifestation of rheumatoid arthritis. In the eight cases that they described the metacarpo-phalangeal and interphalangeal joints showed absorption and squaring of metacarpal and phalangeal heads, cupping of phalangeal bases, loose overlying skin and an "operaglass" finger deformity: other joints showed typical changes of rheumatoid arthritis. In addition there was considerable absorption of carpal bones, and thinning and tapering of the distal ends of the ulnae. Clarke (1950) described typical arthritis mutilans in association with psoriasis.

Faget and Mayoral (1944) described a type of doigt en lorgnette of rather different pathology in neural leprosy. In the hands the distal phalanges are first affected, showing a sliced, nicked or collar button appearance, the middle and proximal phalanges and sometimes the metacarpals being then successively involved, though in the feet the process is apt to start in proximal phalanges and metatarsal heads. The process is one of concentric atrophy with gradual erosion of the cortex and disappearance and calcification of the medullary cavity, until there is left only a fine needle of bone, which may ultimately disappear altogether. In some instances the metatarsals may become shortened and thinned, and their distal ends pointed like a sucked stick of sugar candy. Faget and Mayoral pointed out that this atrophic absorption of phalanges is not exclusive to leprosy, but may occur in such neurotrophic diseases as Raynaud's syndrome, syringomyelia, tabes dorsalis and chronic injuries of spinal cord or peripheral nerves.

Hackett (1951) described two cases of doigt en lorgnette due to yaws. In the first case, which he ascribed to a previous destructive yaws process, the diaphyses of certain phalanges were completely absent, leaving the two terminal articular fragments, and the overlying skin was redundant. The second case showed changes more like those of arthritis mutilans, a destruction of the bone ends constituting the interphalangeal joints with medial deviation at these joints. White (1971) recorded four Vietnamese patients with dissolution of metacarpals, phalanges, and in one case, the carpus accompanied by severe skin scarring and positive serological tests for syphilis.

This report concerns the cases of two Nigerian Africans, in which doigt en lorgnette and a type of concentric bone atrophy were associated with healed yaws.

\section{CASE REPORTS}

Case 1-A man aged thirty was admitted in January 1953. The history was unreliable, but he said that there had been sores on both arms and legs some years before, and that he had had smallpox a year previously. On examination he was severely crippled and bedridden. There were old, pitted smallpox scars on nose and cheeks, and diffuse "tissue-paper" scars 
on the forehead, on the dorsal, medial and lateral aspects of both elbows, on the right antecubital fossa, and on the right thigh. The skin of both legs and feet was shiny and atrophic, and there was a patchy, irregular depigmentation of both shins, typical of old yaws. The surfaces of both tibiae were palpably irregular. There were flexion contractures of both knees with posterior subluxation of the tibiae, and stiffness of feet and ankles with equinus deformity. The muscles felt small and firm, but voluntary power was fair within the limits of the contractures. There were flexion contractures of both elbows. The right forefinger was scarred, shortened and unduly mobile in its proximal segment. There were no abnormal neurological signs or stigmata of leprosy. The Kahn test was positive.

Radiological appearances-There was marked narrowing of femur, tibia and fibula (Fig. 1) and radius and ulna on both sides (Fig. 2), largely at the expense of the medullary canal.

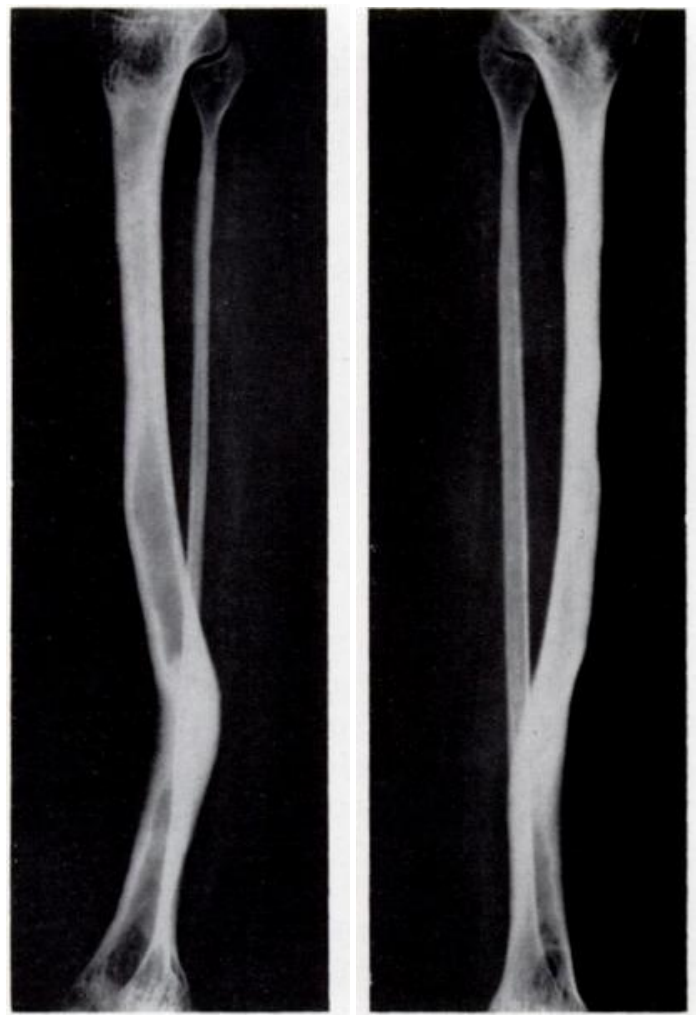

Fig. 1
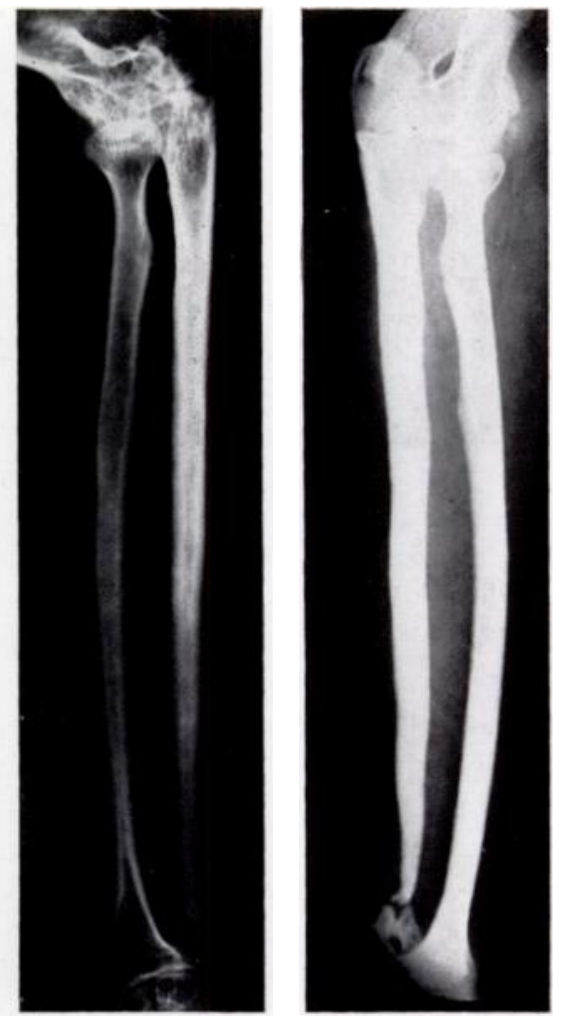

FIG. 2

Case 1. Figure 1-Radiographs of right and left tibiae and fibulae showing combined changes of old yaws osteitis and concentric atrophy. Figure 2-Radiograph of right and left forearms.

The outlines of the tibiae were irregular. The attenuated distal end of the left ulna showed an area of complete dissolution. There was dissolution of the base of the middle and all but the base of the proximal phalanx of the index finger (Fig. 3).

Progress-The lower limbs were straightened by tenotomy of the calcaneal tendons, manipulations and wedged plasters, and the patient was rendered ambulant with calipers and crutches.

Case 2-A man aged about twenty-five years was admitted in June 1954. He described the occurrence some years before of numerous small, consecutive sores on both forearms and legs, which had healed to leave weak, scarred areas of skin. Gradual lateral bowing of the right forearm had subsequently developed. 


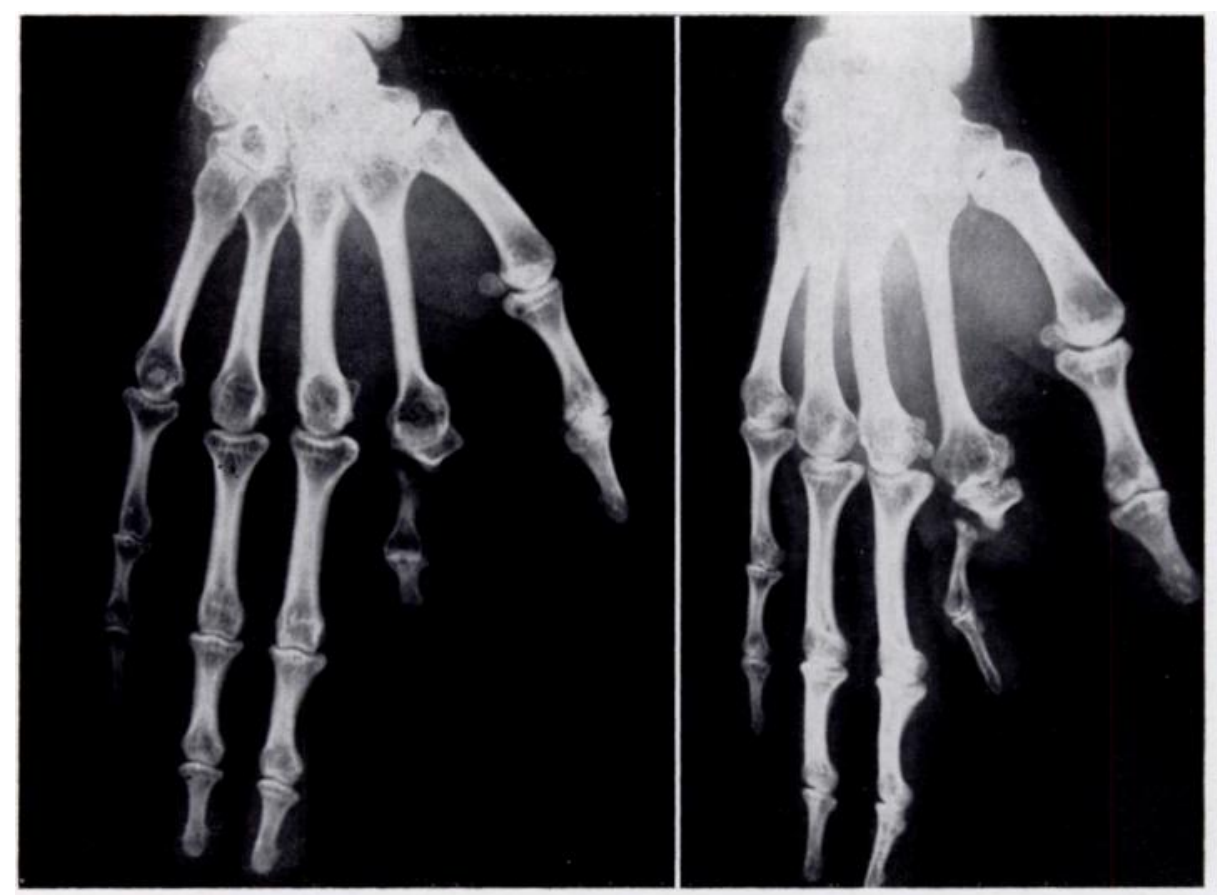

Fig. 3

Case 1-Radiographs of right hand showing index doigt en lorgnette.

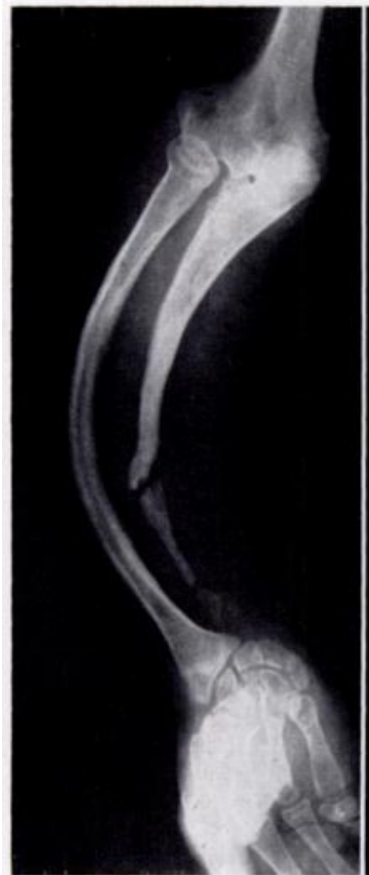

Fig. 4

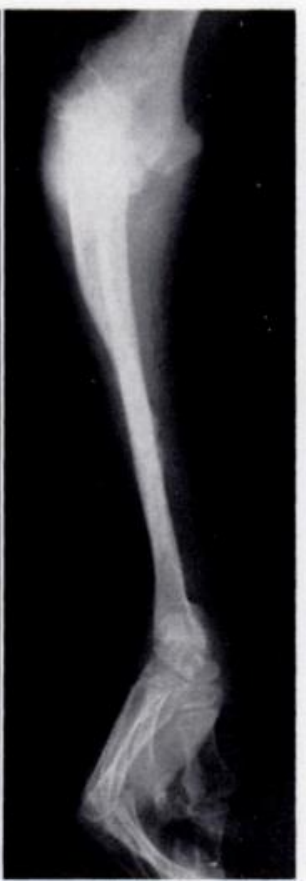

Case 2. Figure 4-Radiographs of right forearm showing bowing of radius, concentric atrophy, and doigt en lorgnette of little finger. Figure 5-Radiographs of right tibia and fibula showing changes of old yaws osteitis. 
On examination he was a fit, well nourished man with extensive tissue-paper scarring on the dorsum of the left elbow, forearm and hand, all round the left wrist, and on the anterior aspects of the left knee, ankle and right leg. Deeper, circumferential scarring of the right ankle had led to an elephantoid condition of the right foot, with recurrent bouts of lymphangitis. There was severe lateral bowing of the right forearm. There was shortening of the left thumb with undue mobility in its proximal segment, and a similar condition of the right little finger and right second toe. The Kahn test was positive $(+++)$ and the Wassermann reaction positive.
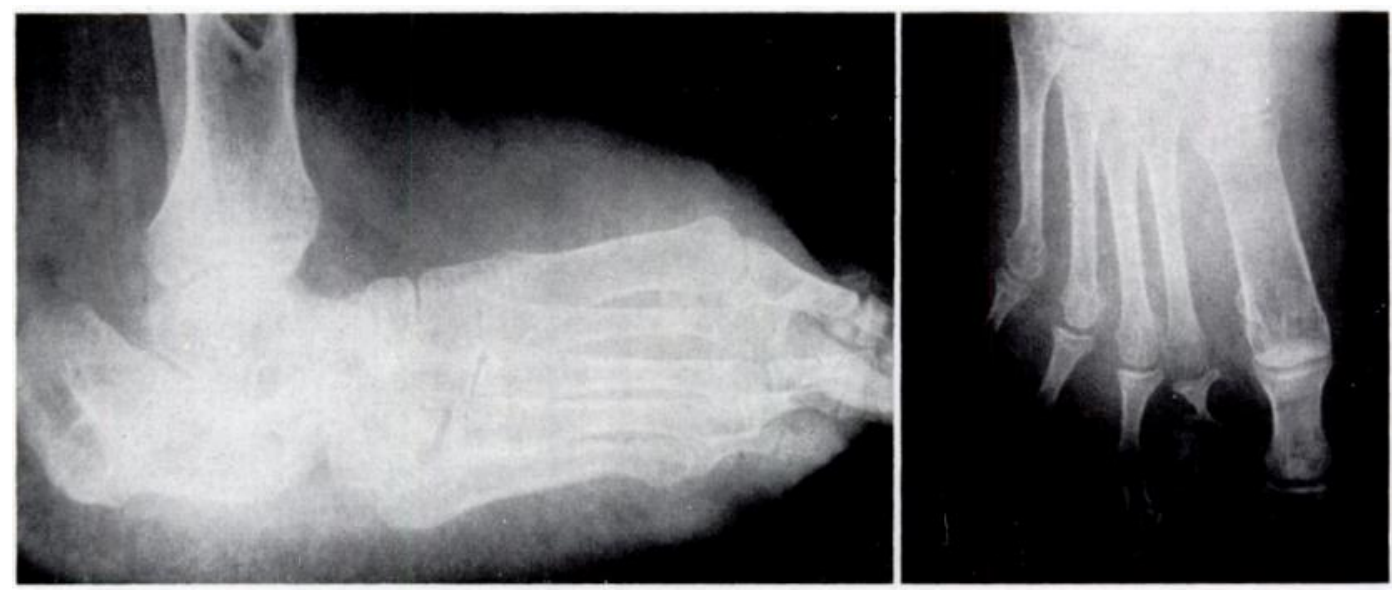

Fig. 6

Case 2-Radiograph of right foot showing doigt en lorgnette of second toe.

Radiological appearances-The right radius was narrowed at the expense of the medullary canal: it was markedly bowed with ulnar deviation of the hand, and the distal epiphysis was apparently still separate (Fig. 4). The right ulna was much attenuated, with areas of complete dissolution. The right lower tibia showed irregular cortical thickening with one circumscribed area of cavitation (Fig. 5). There was shortening and attenuation of the proximal phalanx of the right second toe (Fig. 6) and loss of the diaphyses of the proximal phalanges of the right little finger (Fig. 4) and left thumb.

Progress-Although the right foot was a liability amputation was refused. The dorsum of the foot was flayed and Thiersch grafts were applied, with a satisfactory result.

\section{DISCUSSION}

Although leprosy is common in parts of Nigeria it is unlikely, in the absence of anaesthesia or other leprotic stigmata, that it was the cause of the bone atrophy in these cases. Faget and Mayoral emphasised that the bone absorption of neural leprosy seldom ascends proximal to the metacarpals and metatarsals, and that it is a late manifestation always accompanied by other distinctive signs of nerve leprosy.

On the other hand, these cases present many features suggestive of yaws-the positive Kahn reaction, the history of old sores on the limbs leaving typical tissue-paper scars, and in the first case the reticular, mottled depigmentation of the shins. As for the bone changes, the phalangeal lesions were very similar to those described by Hackett, and the changes in the lower right tibia in the second case were suggestive of old healed yaws osteitis. The tibiae in the first case were very irregular in contour, with a dense cortex and irregularity of the medullary cavity, an appearance consistent with old yaws except for the overall narrowing, in contrast to the thickening of the shaft usually encountered in yaws. The unusual changes in 
the right forearm in the second case could represent the final stage of a lesion illustrated by Hackett (see his Figs. 81 and 82), in which active yaws of the distal radius had caused epiphysial stimulation, overgrowth and medial bowing, while a destructive lesion of the distal ulna had shortened it.

In short it seems probable that in these two cases there was superimposed on a healed yaws osteitis a concentric bone atrophy resembling that encountered in neural leprosy. Faget and Mayoral concluded from arteriographs that no important disturbance of the arterial circulation of the extremities occurred in leprosy, and attributed the bone atrophy to destruction of hypothetical neurotrophic fibres.

\section{SUMMARY}

Two cases are reported in which doigt en lorgnette was associated with features of longstanding yaws. Radiographs showed an unusual bone appearance, believed to be due to superimposition of concentric atrophy with focal dissolution of the distal bones on the lesions of healed yaws osteitis.

I wish to express my thanks to the Honorary Chief Medical Adviser to the Federal Government of Nigeria, Sir Samuel Manuwa, for his permission to publish this paper.

\section{REFERENCES}

Clarke, O. (1950): Arthritis Mutilans Associated with Psoriasis. Lancet, i, 249.

FAGet, G. H., and Mayoral, A. (1944): Bone Changes in Leprosy. Radiology, 42, 1.

HACKetT, C. J. (1951): Bone Lesions of Yaw's in Uganda, p. 153. Oxford: Blackwell Scientific Publications.

MARIE, P., and LÉRI, A. (1913): Une variété rare de rheumatism chronique: la main en lorgnette. Bulletins et Mémoires de la Société Médicale des hôpitaux de Paris, 36, 104.

Solomon, W. M., and Stecher, R. M. (1950): Chronic Absorptive Arthritis or Opera-glass Hand. Annals of the Rheumatic Diseases, 9, 209.

White, A. A., III (1971): Disappearing Bone Disease with Arthropathy and Severe Scarring of the Skin. Journal of Bone and Joint Surgery, 53-B, 303. 